\title{
Talking about prejudice. A project for the nursing courses
}

\author{
Gradellini Cinzia* \\ Università di Modena e Reggio Emilia/Azienda Unità Sanitaria Locale-IRCCS di Reggio Emilia, Reggio Emilia, Italy
}

\begin{abstract}
- The literature suggests nursing courses in to adopt curricula to support the specific competences requested to care migrants.

- One of the recommended topic is the consciousness' promotion of the prejudice, because it becomes the key component of several problems: coexistence, acceptance, communication, and discrimination.

- The described teaching module "Talking About Prejudice", planned for the nursing courses, has the objective to develop the consciousness of the tendency to generalize people, to, finally, arrive at the prejudice management.
\end{abstract}

\section{Introduction}

Considering the migration phenomenal, the human rights' related question is still a bullet point for the person's respect and it has a leading role, in terms of rights to life, equality, freedom of movement, and freedom of thinking [1].

The level of fragility of the migrant people is extreme, especially for what concern the state of the health, regardless of the presence of a disease. Therefore, this requests a competent care, both in term of clinical and socio-cultural approaches. This is why the health context requested competences for an effective action, made by the organization, and the professionals, which starts from the interaction of different values, behaviors and beliefs [2]. These competences appear really complex, and they need an appropriate preparation, already from the basic training, in terms of knowledge of cultural differences, ability to explore the diversity with specific practical skills [3] and with research programmes [4].

In the literature, the effectiveness of the introduction of teaching modules of Transcultural Nursing is often confirmed [5,6], even if a review suggests them only if the modules are used as a unique strategy to combat racist attitudes [7]. When it has been talking about cultural awareness and competence, the literature suggests different strategies of teaching. Between these, problem based learning about social and health inequalities, creating awareness among vulnerable populations, and dealing with topics as social justice, cultural competency and cultural security, are -generally- recommended [8]. Another review suggests the importance to start from the centrality, in the care, of the person, the family and the community [9].

Although it emerges an improvement of the intercultural didactic modules available in the health professions' Courses, common problems come out: the lack of consensus about what it is necessary to teach, the lack of reference standards, the lack of a formal evaluation of the didactic proposals' evaluation [10,11]. Therefore, this should calls the courses in to adopt curricula to support the specific competences [12], among them the consciousness' promotion of the prejudice [13,14]. Facing the social complexity, which characterises the migration's context [15], the prejudice becomes the key component of several problems: coexistence, acceptance, communication, and discrimination ([16].

\section{The teaching module "Talking About Prejudice"}

Since several years, the project "Talking About Prejudice" has been proposed to the last-years' nursing students of different university courses in Italy, Belgium Netherlands, and Finland. Because these courses have been part of project working on the courses' internationalization (e.g. Erasmus teachers' exchanges) they were taught in English language. The module has been proposed in different ways: as a curricular activity, as an optional activity, and in international workshops.

In the last years about five-hundred students have been participated, divided in groups of twenty/thirty people.

The main objective of the course, shared with the students at the beginning of the module, is to be consciousness of the tendency we have in to generalize people who are not part of the group we belong (ingroup).

The module is divided in three parts, lasting one hour each and divided in: 1) basic concepts; 2) prejudice's analysis; 3) prejudice management.

To introduce the main objective, a few parts of videos from CNN (Cable News Network) are showed to the students. They give folks a taste of what happened during the major terrorist attacks of the last years (Paris, Brussel's Airport and Barcelona). This choice could seem a long shot, but it is useful to start from people's fears. After the videos (15 minutes in total) a debriefing, about the aroused emotions follows; the emerging ones, shared by the students, are fear, shock, fragility, perception of unsafety in the daily life. This first sharing is not easy, especially considering the beginning of the module, and the fact it

${ }^{\star}$ Correspondence to: Gradellini, Cinzia, Università di Modena e Reggio Emilia/ Azienda Unità Sanitaria Locale-IRCCS di Reggio Emilia, Reggio Emilia, Italy, E-mail: cinzia.gradellini@ausl.re.it;

ORCID: https://orcid.org/0000-0002-9574-8550

Key words: prejudice, stereotype, nursing, education, mass media

Received: August 26, 2020; Accepted: September 15, 2020; Published: September 18, 2020 
is in English (instead that in mother language), but students always participate, confirming the need to talk about this argument.

This first sharing permits to legitimize the incoming emotions, in terms to understand they are a normal reaction to these facts. Everyone is scary of these events, everyone feels unsafety, but thanks to the emotions' recognition, it is possible to work on them. The main point is the consciousness of the fear itself, and of the defence mechanisms it actives. This consciousness lets to start the critical analysis of what is going on, first of all, the generalization which normally come through. The importance of this is that generalization reduces our world view: a nice example, proposed to the students, is the narration about the meeting of the musician Frank Zappa with the anchor man Joe Pyne. When the ex-marine and disabled veteran saluted Zappa telling: "Frank, you have long hair. Does that make you a woman?", Zappa answered that a wooden leg doesn't make a table of him [17].

\section{The basic concepts}

The concepts of culture, stranger, and identity are introduced using a brainstorming; from students' suggestions it has to emerge a shared definition of these terms.

About culture's definition, all the students' proposals are -usuallycorrect, in fact, more than two hundred definitions are available in literature, and divided in categories [18]. Culture is a really complex concept, which includes several aspects, that's why it could be represented as an iceberg. It is composed of a visible part, and of a hidden part; the first part, above the sea level, is known by everyone, and it includes, as an example, language, skin colour, expressions, tattoos. The hidden part, under the sea level, is known only in the group people belong, but it is the biggest one, and it includes the gender, the role, the concept of family, justice, beauty or justice [19].

Starting from this point, the culture has to be considerate as mosaic: every human being is characterized -and he/she has to be consideredas made by many different cultures. These cultures could be national, regional, ethnic, gender, generational or "whatever" [20]. It is easy to understand this concept about what concern ourselves, or our-group's members, but what happens, is a trend to do not recognize this same complexity in the other, as we normally do for ones who are part of our group. This defensive model of "cosmic provincialism" [21] is an inability in to recognize, in the other, the same identity complexity described above. Once again, this bring us to the consciousness of the generalization we apply when we meet the differences.

In our daily life, the culture becomes a filter by which people see and understand the world, a filter by which they arrive to choose the other people, or to avoid them. Outside of this choice, there is the stranger, "someone who could upset the shared behavioural models, who could compromises serenity, and who can confuse borderlines (which normally have to be really defined)" (Ibidem). Each group builds its own idea of stranger, each one different from the others' one (Ibidem), and each people becomes stranger of someone else [22].

In relation with the idea of who the other is, there's the concept of who I am, which results the definition of the term identity [23]. This concept underlines a meaning of being someone (or something) irrespective of the context's changes. Despite that, what often happens, nowadays, is the description of the identities as something that has to be built, and protected, with efforts and fights [24]. Each time the identity's difference is underlined in any manner, borders are underlined and real or conceptual walls are built, bringing shutting and conflicts. Each time it has been told about identity's defence, it has been obtained just an increase of the differences, and these risk to become impassable [21].

\section{The Prejudice Analysis}

The second part of the module is introduced by an exercise [25] in which a students have to categorise objects of an everyday sort (e.g. money, keys, mobile phone, bus ticket). A volunteer has to form and show to the class his/her own categories, without express the underlying reasoning. At the end, together the class has to: 1) reflect on the possible reasoning, trying to find out common choices; 2 ) reflect to the facility of doing categories; 3 ) reflect on the possibility to categorize people as we made with the objects; 4) think how and why people use to do this. The discussion bring students to the consciousness we might need to categorize people when we don't know them, and we do this using stereotypes and prejudices.

To introduce the stereotype's concept, a few imagines from the book "Atlas of Prejudice" by Yanko Tsvetkov [26] are used to show example about how the world looks at everyone is considering the "rest of the world". On the geographical representation of that, students can easily catch how weird could be to someone else's eyes something resulting part of our "normal" life (e.g. Culinary Map of Europe according to Italy). The stereotype is a model to read the context, which simplify the realty: the behaviors of the ingroup's members are codified through specific categories, while the outgruop's ones through general categories [27].

For what concern the prejudice, some theoretical elements are introduced. The first psychological studies about the ethnical prejudice (1954) describes it as a dislike based on an irreversible generalization toward a group or toward an individual, just because part of a specific group [16,28]; the tendency in to considerate each outside element as lower, seems to emerge [28]. More recent studies describe the prejudice as the maintaining of deskilled social attitudes and cognitive beliefs, coupled with the expression of negative emotions, or hostile/ discriminatory behaviours toward people of a specific group [29], just because they are part of it. This phenomenal starts from a tendency in to classify people, considering the group they belong [30], or considering evident characteristics, shared as something known, meeting or not the standard [31]. The simplified imagine becomes a category and it boosts stereotype and prejudice [32].

The prejudice has to be considerate a defence mechanism toward something unknown which intimidates precisely because not-known. It has a cognitive component (the stereotype), an emotional and motivational component, which means the defence's action, but also the expression of a judgement. The judgement could move to an action which becomes discrimination, as behavioural component of the prejudice itself.

It is possible to recognize a manifest prejudice (e.g. discrimination), or a subtle one, which is really common [33]. This last is observable in an own-culture values' defence, in a strong adhesion to the tradition, exasperation of differences and aversion to politics of migrants' acceptance [16,33-35]. At the base of these types of prejudice, there is an element of social desirability which is the expression of the need to maintain a positive self-image.

A key point is that the prejudice is instinctive, as a defence mechanism from something (or someone) people are afraid of. This means it is not possible deciding to do not perceive it, but it's possible to work on it, starting from its consciousness and analysis.

A brainstorming introduces what or who determines a prejudice, elements that are: 1) the lack of personal experience or personal knowledge; 2) the culture where people live (in terms of micro and macro context);3) the media system. 
The reflection about the cultural macro-context is introduced looking at different world maps. Since 1154 Muhammad Al-Idrisi, a Moroccan geographer, completed an atlas of maps (Kitab Rujar) in which the regional ones where all oriented southwards, to consider on top the direction of Mecca [36]. The Hereford map, located in the cathedral which has the same name, dates back to the late 1200, and it is attributed to the Richard Haldingham, a Christian cartographer [37]. The characteristic of this map is that we can find the East on top, because the paradise was considered in the same direction of the dawn. Three-hundred years later, Gerardus Mercator, a Flemish mathematician, and astronomer, drew an Europe-centric map in which Africa and South America are much smaller than they actually are [38]. In the more recent map of Peters (1967), maintain an Europe centered view, but because drew in the post-colonization period, Africa became more important, therefor bigger [39]. Certainly not all maps are Europe cantered; if we look at the Phoenix International one, Unites States are central, if we consider the Australian map, we could see the world turned upside-down, so this country becomes on top. These reflections open the discussion about the shared world view of each population, influenced by the cultural frame (e.g. country of leaving, religion, political and historical situation).

Another suggestion about the individuality of world view is the book "Papalagi" [40], the description of the white man (the papalagi) made by a tribal chief of the Samoan island, in 1920, at his first visit to Europe. Another suggested reading is "Stupid White Man" [41] which permits to discuss about the influence we are used to have from the cultural micro-context, which could means family, relatives, friends. In a chapter of this book, Moore tries to explain we've been lulled into thinking it's safe to be around other people like us, and that we've need to fear people of other colours, even without understand why. Also he brings the attention on the fact we are use to see, on media, black people kill and die, and we are getting accustomed to this, as it was a "standard procedure" (Ibidem). This element brings to the last, but not least, cause of prejudice: the media system.

This big paragraph is introduced showing a slide show of photos coming from the media-system itself. These pictures have a common topic, which is the different people or the other from us, and they are all coming from the media system, considering both chronicle and commercials. Starting from this visual suggestions, students have to find out where the images are from, which is the common subject (different cultures), and what are the related messages. The key point is that the media system describes or represents the different cultures as something sometimes, but even as really scary, to control, and manage the public opinion. In the specific of the positive message (e.g. beautiful African or Chinese people dressing suits who became more fascinating thanks to their skin colours), it is use to sell a product, and to earn money. Instead, the negative message responds to a strategy, known as strategy of fears [42]. To earn votes and power (always related to money) the media system works increasing the feeling of insecurity and scare, which is related to the need of someone able to protect.

Media's controlling is becoming fundamental to control a democracy [43], but not only that: people should be aware of the fact that "the peace is not erasing the Gross Domestic Product, and multiculturalism makes earn money only in the football" [44], perhaps even in the fashion world. That's why we have to be aware of the fact that "the related reasons are economic: hate and fear make earn votes, and the inequality let, a small part people, to accumulate fortunes" (Ibidem). Moreover, the manipulation of the information to get political goals, could arrive to justify wars. In the history lots of sad examples emerges, where it has been created a shared model of barbarian as human enemy, and to eliminate it resulted the only way to survive, so it has been necessary [45].

Several journal articles are presented to the students, as a complaint of a need of an independent press (e.g. Massimo Cacciari, Charb Stéphane Charbonnier, Michel Chossudovsky, Anna Politkovskaja, Stefano Rodotà), along with the report of the association Freedomhouse. org. Its annual report presents the global press freedom rankings, divided world countries in not free, partly free and free [46].

The conclusion of this part, shared with the students, is to use the critical thinking in approaching facts and news, and each time the information about what is going on is approached.

\section{The Prejudice Management}

The Nine Dots Puzzle [46] is used to introduce the last part of the module. This exercise stimulated a reflection about the difficulty to work on it, which means the difficulty to see a new element outside from our cultural frame. The first time this game is approached, there's a tendency in remain in the square of the game itself, and this reflects the frame in which we close ourselves. The first suggested thing, to manage a new situation or element, is having consciousness of the prison in which people close themselves, giving a name to the prison itself. Karl Popper described these prisons as frameworks, determinate by our own intellectual context (e.g. culture, in the wider meaning of the term previously discussed). The way in which people arrive to the truth is conditioned by the aprioristic knowledge they have, founded on personal opinions. The people who do not want to be prisoners, of the culture frame, need to oppose them [48] and to do this it is necessary to start from the consciousness.

Sagir Whorf wrote that we live in an intellectual prison made by structural rules of our language; the way to become consciousness of these prisons is having a crash between cultures, which could permit a contamination of rules, thoughts, points of view. In other words, the consciousness is the way to get out from the prison itself [20].

If we consider the prejudice as a type of prison, the first step to manage it, is to have consciousness of it, starting from its understanding. This means trying to understand what it is, where it comes from, what has been caused it).

The second important step is to give to ourselves the permit to feel this analysed prejudice, starting from the point it is instinctive, and a defence mechanism we cannot decide if perceive it or not. This helps in being aware of what we are thinking about a "new" person or a new situation, and it opens to the real encounter [49].

The module is concluded with a game named "Guess who are coming for dinner". Starting from a list of possible participants, only described by the country of origin, and by the sex, the students have to decide three people with who to share a dinner table. Once done the list, they discovery the real identity of them, totally outside the standard stereotype. The final message is to remember to be alert and to do not let the intellectual frames influence too much the life choices [50-55].

\section{Conclusion}

The evaluation of the project has been made using the sticky wall method, which allows a qualitative feedback from the group. At the end of the module, it has been requested to the students to write, on a post-it, a key-point's sentence or word about the module, and to leave it on the wall before leave the class. This method gave always positive 
references, mostly whit comments related to the open-minded effect of the module. Also, the students' participation in class has been always really active. The discussion is rich of suggestions, and students are totally involved.

Each year the project it has been reviewed and updated in relation with the social and political changes all over the world.

The relevance of the contents and the integration with the active learning methods, make the teaching module being appreciated by students and it permits to get the learning outcomes.

The respect of the individuality and of the differences is the basis of the health care. Starting from this point, students and health professionals are called upon to be prepared in manage the hard work requested when they are working in a multi-cultural context. The consciousness of the prejudice is a key point which supports the inter-culture communication, and which allows to recognize the other, doesn't matter how much different from us, he/she could be. The development of this form of other's respect is the assumption to a cultural-competent care, and, at the same time, a guarantee of a real patient-centred approach.

\section{Funding}

None.

\section{Conflict of interest}

None.

\section{Ethical approval}

Not requested.

\section{References}

1. United Nation (1948) Universal Declaration of Human Rights.

2. Chiarenza A (2012) Developments in the concept of cultural competence. Inequalities in health care for migrants and ethnic minorities 2: 66-81.

3. Taylor G, Papadopoulos I, Dudau V, Maerten M, Peltegova A, et al. (2011) Intercultural education of nurses and health professionals in Europe (IENE). Ins Nurs Rev 58: 188195. [Crossref]

4. Maddalena V (2009) Cultural competence and holistic practice: implications for nursing education, practice, and research. Holist Nurs Pract 23: 153-157. [Crossref]

5. Flood JL, Commendador KA (2016) Undergraduate nursing students and cross-cultural care: A program evaluation. Nurse Educ Today 36: 190-194. [Crossref]

6. Bohman DM, Borglin G (2014) Student exchange for nursing students: Does it raise cultural awareness'? A descriptive, qualitative study. Nurse Educ Pract 14: 259-264. [Crossref]

7. Allen J (2010) Improving cross-cultural care and antiracism in nursing education: A literature review. Nurse Educ Today 30: 314-320. [Crossref]

8. Rozendo CA, Salas AS, Cameron B (2017) A critical review of social and health inequalities in the nursing curriculum. Nurse Educ Today 50: 62-71. [Crossref]

9. Montenery SM, Jones AD, Perry N, Ross D, Zoucha R (2013) Cultural competence in nursing faculty: A journey, not a destination. J Prof Nurs 29: e51-e57. [Crossref]

10. Lipson JG, DeSantis LA (2007) Current approaches to integrating elements of cultural competences in nursing education. J Transcult Nurs 18: 10S-20S. [Crossref]

11. Sealey LI, Burnett M, Johnson G (2006) Cultural competence of baccalaureate nursing faculty: are we up to the task? J Cult Divers 13: 131-40. [Crossref]

12. Garneau AB (2016) Reflection in Cultural Competence Development: A Framework for Undergraduate Nursing Education. J Nurs Educ 55: 125-132. [Crossref]

13. Gordon WM, McCarter SA, Myers SJ (2016) Incorporating Coursework into a Cultural Competency Curriculum. J Midwifery Womens Health 61: 721-725. [Crossref]
14. Calvillo E, Clark L, Ballantyne JE, Pacquiao D, Purnell LD, et al. (2009) Cultural Competency in Baccalaureate Nursing Education. J Transcult Nurs 20: 137-145. [Crossref]

15. Zanier ML (2001) L'analisi del pregiudizio moderno tra questioni di definizione e aspetti metodologici. Il caso degli immigrati stranieri. Polis 1: 79-100.

16. Cariota Ferrara F, La Barbera F (2008) L'effetto del conflitto realistico su pregiudizio sottile e manifesto: il caso cinese. Presentation at the conference "Spazi interculturali trama, percorsi, incontri”, Roma.

17. Miles B (2004) Frank Zappa. London: Atlantic Books Ltd.

18. Allaire Y, Firsirotu ME (1984) Theories of organizational culture. Organization studies 5: $193-226$.

19. Hanley JH (1999) Beyond the tip of the iceberg. Reaching today's youth. The Community Circle of Caring Journal 3: 9-12.

20. Whorf BL (1977) Linguaggio, pensiero e realtà. Torino: Boringhieri.

21. Aime M (2004) Eccessi di culture. Torino: Einaudi.

22. Ben Jelloun T (2017) Il razzismo piegato a mia figlia. Milano: La nave di Teseo.

23. https://dictionary.cambridge.org

24. Bauman Z (2005) Intervista sull'identità. Roma-Bari: Editori Laterza.

25. Bennet M (2002) Comunicazione interculturale: una prospettiva corrente; Superare la regola d'oro: simpatia e empatia. In M. Bennet (a cura di), Basic concept of intercultural communication: A reader. Yarmouth, ME: Intercultural Press.

26. Tsvetkov Y (2013) Atlas of Prejudice: Mapping Stereotypes. Alphadesigner.

27. Park B, Rothbart M (1982) Perception of out-group homogeneity and levels of social categorization: Memory for the subordinate attributes of in-group and out-group members. Journal of Personality and Social Psychology 42: 1051-1068.

28. Allport GW (1973) La natura del pregiudizio. Firenze: La nuova Italia.

29. Brown R (1995) Psicologia sociale del pregiudizio. Bologna: Il Mulino.

30. Worchel S, Cooper J, Goethals GR (1991) Understanding social psychology. (5th Edn) The Dorsey Press, Homewood.

31. Cattani R, Liguori M (2007) La rappresentazione sociale dello straniero e la componente cognitiva del pregiudizio. Sociologia e Ricerca Sociale 83: 41-59.

32. Aletto L, Di Leo L (2003) Nursing nella società multiculturale. Roma: Carocci Faber 2: 168 .

33. Pettigrew TF, Meertens RW (1995) Subtle and blatant prejudice in Western Europe. European Journal of Social Psicology 25: 57-75.

34. Manganelli AM, Canova L, Bobbio A (2008) Giornale di Psicologia 2: 131-141.

35. Arcuri L (1992) Razzismo: il pregiudizio automatico. Psicologia Contemporanea 112: 47-92.

36. Dohrn-van Rossum G (2011) Al-Idrīsī and His World Map (1154). In Jalagin S, Tavera S, Dilley A. World and Global History: Research and Teaching. Pisa: Plus-Pisa University Press.

37. Harvey PD (1996) Adshead Mappa mundi: the Hereford world map. Toronto University of Toronto Press.

38. Tobler WR (1978) A Proposal for an Equal Area Map of the Entire World on Mercator's Projection. The American Cartographer 5: 149-154.

39. Robinson AH (1985) Arno Peters and his new cartography. The American Cartographer 12: $103-111$.

40. Tuiavii di Tiavea Papalagi (1998) Roma: Stampa Alternativa.

41. Moore M (2003) Stupid White Man. Milano: Mondadori, Strade blu.

42. Breckenridge JN, Zimbardo PG (2007) The strategy of terrorism and the psychology of mass-mediated fear. Psychology of terrorism pp: 116-133.

43. Roy A (2006) The very strange story of the attack on the Indian Parliament. Milano: Guanda.

44. Dandini S (2015) La guerra conveniente. Io/Il corriere della sera.

45. Cacciari M (2012) Il barbaro che verrà. La Repubblica.

46. http://freedomehouse.org

47. Partridge D, Rowe J (1994) Computers and creativity. US: Intellect Books. 
48. Popper RK (1995) Il mito della cornice. Difesa della razionalità della scienza. Milano: Il Mulino.

49. Gradellini C, Artioli G (2006) L'utilizzo del Counseling nella gestione del pregiudizio. Nursing Oggi 3: 18-22.

50. Bradbury R (1953) Fahrenheit 451. Milano: Mondadori.

51. Clinton JF (1996) Cultural diversity and health care in America: Knowledge fundamental to cultural competence in baccalaureate nursing students. $J$ Cult Divers 3: 4-8. [Crossref]
52. http://frontexeuropa.eu

53. Frontex (2018) Migratory flows in June: Total number drops, Spain sees the biggest number of arrivals.

54. Weaver M (2015) Refugee crisis: EU plans new internment measures.

55. Van Voorhis WCR, Morgan BL (2007) Understanding power and rules of Thumb for determining sample sizes. Tutorials in Quantitative Methods for Psychology 3: $43-50$.

Copyright: (C2020 Cinzia G. This is an open-access article distributed under the terms of the Creative Commons Attribution License, which permits unrestricted use, distribution, and reproduction in any medium, provided the original author and source are credited. 